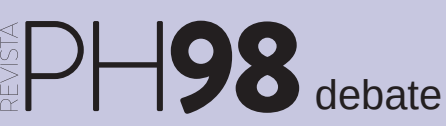

a debate ¿Hay patrimonio sin comunidad? Despoblamiento, turistificación y patrimonio cultural

| coordina Jaime Jover Báez

\title{
Aprendiendo de las antípodas
}

David Pascual | arquitecto y estudiante del Máster en Arquitectura y Patrimonio Histórico de la Universidad de Sevilla

URL de la contribución <www.iaph.es/revistaph/index.php/revistaph/article/view/4504>

Cuando llegamos a Nimbin, entre las montañas de la costa Este australiana, nada hace pensar que estemos en la población que antaño fue estandarte del movimiento y estilo de vida hippie en este país, un lugar donde familias llegadas de todas partes iban a desarrollar una vida conforme a su filosofía, de libertad y transgresión de lo establecido, con el centro en un sentimiento de comunidad y justicia y la idea de educar a sus hijos de manera diferente, como Ben Cash en la excelente película Capitán Fantástico.

La necesidad de resignificar en España la vida en los pueblos desde una perspectiva holística e innovadora y atajar así frontalmente el tema de la despoblación rural en Andalucía surge desde la plena actualidad, recogiéndose el desafío trascendental de la despoblación en diversos artículos (DONAIRE, 2012), como el principal tema que afectará al desarrollo futuro de la cultura, economía y calidad de vida en esta región. Sin embargo, no es este un problema en el que la región andaluza esté sola ni al que la Unión Europea sea ajena. Existen

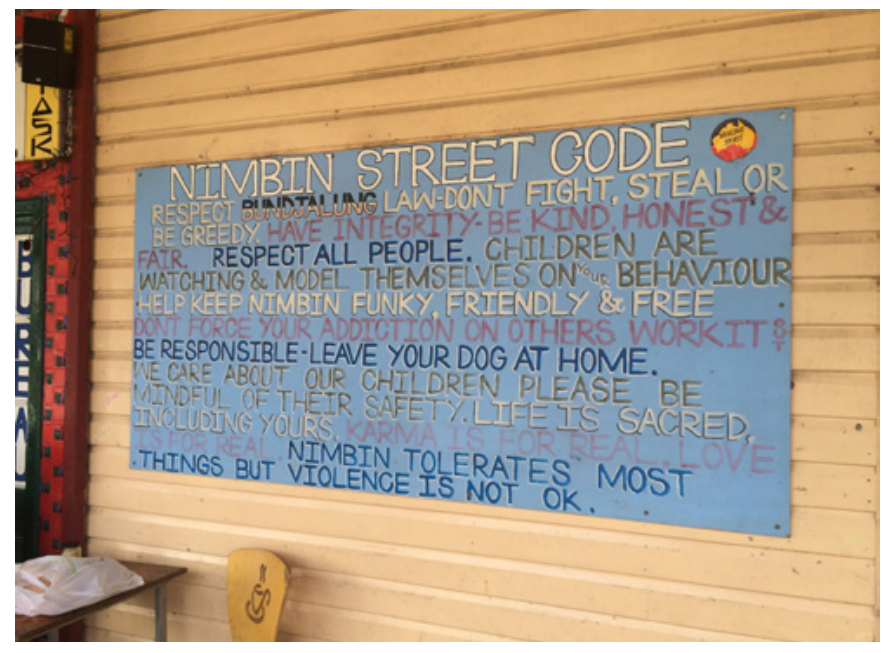

Nimbin Street Code | foto Finn Pröpper en la actualidad diversos programas europeos en marcha para poner solución al problema, como el programa ESPON 2020 (EUROPEAN COMMISION, 2015) o el programa Leader (MATEO PÉREZ, 2018), los cuales es fundamental conocer antes de pasar a la acción, teniendo presente la necesidad de producir resultados tangibles.

En el marco altamente globalizado en el que vivimos, llama la atención que las repoblaciones de los grandes países coloniales hayan en las últimas décadas resultado más exitosas que la vivificación de las tierras del viejo continente, tan rico en un patrimonio que podría actuar como punto base para una dinamización cultural que activase los territorios con un mayor contenido identitario.

Un objetivo deseable en esta dirección sería añadir evidencia territorial al ya iniciado camino para la creación de unas políticas que generen activación y desarrollo en las áreas rurales, no exclusivamente desde una economía agraria y prestando especial atención a la salvaguarda de la identidad y elementos patrimoniales materiales e inmateriales. Para ello, el primer paso sería desterrar esta idea fuertemente arraigada en el imaginario español de que en el campo no hay futuro ni progreso. De que quien tenga ambición ha de hacer las maletas para abrirse camino en Madrid o Barcelona o Londres. Esta idea agoniza. Las grandes metrópolis actuales ofrecen de manera general escasas oportunidades para que los jóvenes formen familias. La natalidad decae, la superficie de la vivienda también, al mismo tiempo que aumenta la población en edad de jubilación. Una inversión de la pirámide de población para la que las grandes ciudades no están ofreciendo ninguna solución realista.

Es necesaria una ampliación del conocimiento en sus vertientes teórica y práctica a través de un análisis multi- 
disciplinar del problema, donde además de antropólogos y urbanistas, entren sociólogos, arquitectos, historiadores, filósofos, biólogos, geógrafos, arqueólogos e incluso agitadores folclóricos. Además, la recopilación de datos, muchos datos, basados en las necesidades de los habitantes para poder formar una imagen realista de cuáles son las debilidades, amenazas, fortalezas y oportunidades de estas áreas. Tras esta valoración, se podrían extraer unas conclusiones propias que se compartirán con los organismos correspondientes para hipotetizar sobre la viabilidad de su aplicación de manera institucional, que por el momento es la manera más efectiva de producir el cambio, aunque no el más dinámico.

Lo que se quiere aprender de las antípodas es cómo la ligereza en el discurso no ha de ser necesariamente negativa. Esa actitud de can-do y el no-worries australianos suponen un aprendizaje clave para reactivar estas poblaciones. La percepción digital que lo invade todo es una poderosa arma en este sentido. Lo rural todavía se ve arcaico, pero encontramos voces nacionales como Rodrigo Cuevas, que con su agitación folclórica supone una invitación a esta vuelta a los orígenes. Ya no es necesario que la generación millennial se mude a Berlín para disfrutar de un festival transgresor. Surgen cada vez más en pueblos españoles, y con las políticas adecuadas estos expatriados millennials hiper formados y exigentes podrían tener una estructura desde la que desarrollar su talento en territorio patrio, para beneficio de todos.

Haciendo un rápido análisis demográfico y social del entorno rural en Andalucía encontramos poblaciones que presentan diferentes problemas. Llama la atención del autor que Andalucía presente una gran resiliencia natural al despoblamiento, especialmente al comparar con otras áreas de España como Aragón. No obstante, las provincias de Granada y Jaén despuntan, con amplias zonas como la comarca de Guadix y Las Alpujarras, donde se enfrenta a una gran riqueza natural y patrimonial una economía ralentizada, agonizante y extremadamente vulnerable a las dinámicas globales. Como si estuviéramos en un laboratorio, y teniendo presente la diferencia entre los entornos de estudio, se inyectan en un ejercicio hipotético los parámetros de éxito australianos o desencadenantes en estos territorios de Andalucía para estudiar la apertura de oportunidades y posibilidades que esta inserción brinde.

Se debe prestar especial atención al hecho de que una población es un conjunto complejo de organismos interconectados políticos, sociales, económicos, culturales, naturales, etc. Así, este ejercicio tendría en cuenta la repercusión que la aplicación de medidas en un campo pueda tener sobre el resto.

Los resultados obtenidos podrían servir como base para una mayor profundización y amplitud de campo de estudio en una temática que puede generar fructíferos resultados para la consolidación de Andalucía como espacio productivo en el globalizado marco actual. Se espera que esto pueda dar pie a una difusión digital y física, cuyos hallazgos sean de interés en el actual debate sobre el despoblamiento rural en Andalucía. Particularmente se intentará involucrar activamente a los municipios seleccionados para potenciar la creación de políticas a través de evidencia territorial. Será esta una relación recíproca, de la que la investigación se nutrirá, manteniendo su centro en problemas reales y no teóricos.

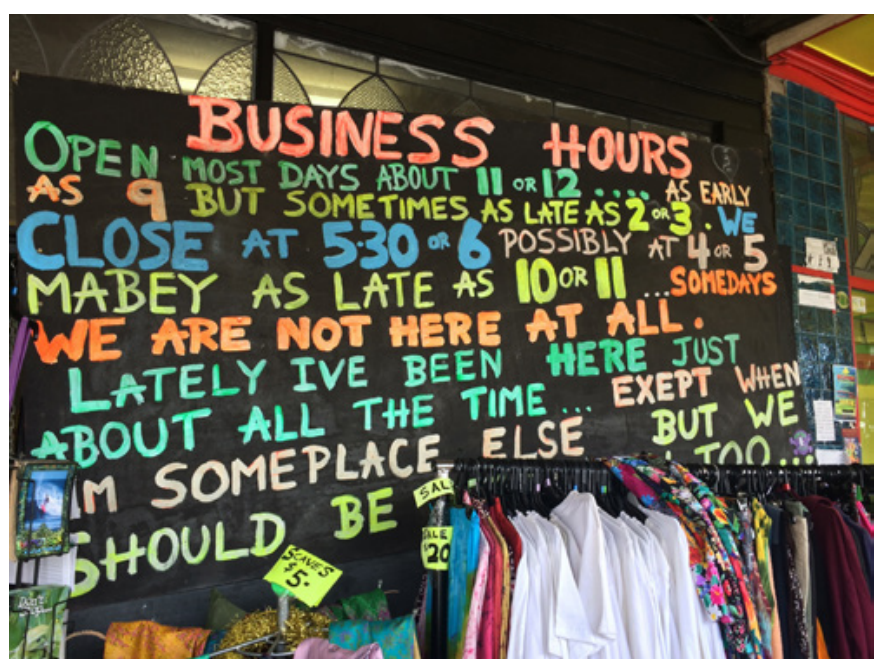

Horas de apertura comercial en Nimbin | foto Finn Pröpper 

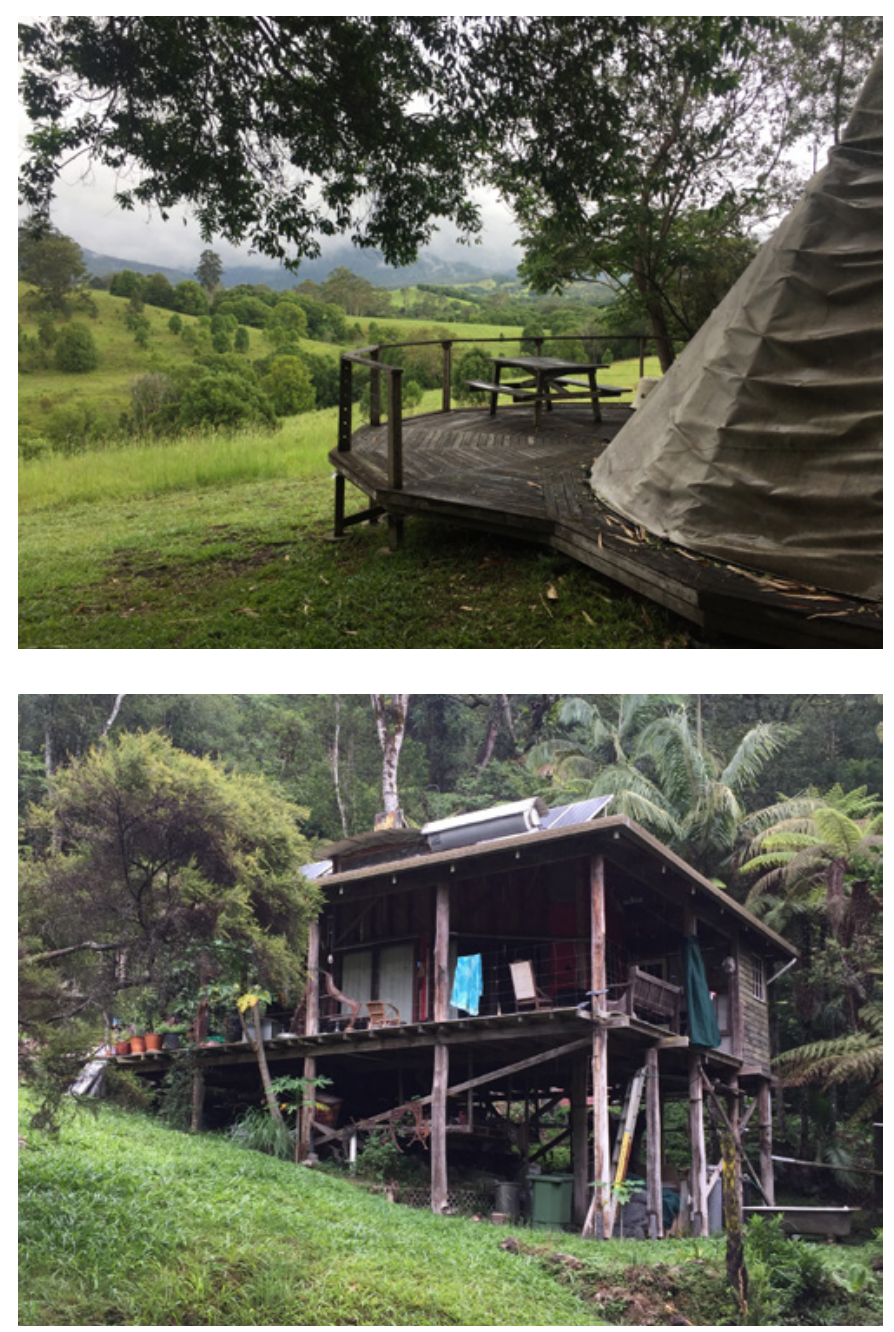

Nimbin, adaptación respetuosa con el entorno natural (superior); autoconstrucción autosuficiente (debajo) | fotos David Pascual

El impacto esperado es conseguir unas conclusiones que representen una innovación en el campo y que procuren una mayor visibilidad a una problemática que permanece en segundo plano por su realidad dispersa, pese a que su volumen y relevancia atañen a la mayoría del territorio. Es urgente tomar medidas para que nuestros territorios no se despueblen. Lo primero es un cambio de mentalidad y del pensamiento, si logramos ver que el futuro está en la vuelta al campo, tanto en términos de salud, como sostenibilidad, y economía, no habrá límites para el desarrollo de la región andaluza.

\section{BIBLIOGRAFÍA}

- ASCASO, L.; GALVAN, I. (1991) Núcleos deshabitados en Andalucía. Sevilla: Consejería de Obras Públicas y Transportes, Junta de Andalucía, 1991

- CAMARERO, L.; CRUZ, F.; GONZÁLEZ, M.; DEL PINO, J. A.; OLIVA, J.; SAMPEDRO, R. (2009) La población rural en España. De los desequilibrios a la sostenibilidad rural. Barcelona: Fundación La Caixa, 2009

- DONAIRE G. (2012) La pérdida de población en el medio rural se agravará en dos décadas. El País Andalucía [en línea], 5 de agosto de 2012 <https://elpais.com/ccaa/2012/08/05/ andalucia/1344164858_535605.html> [Consulta:18/07/2019]

- EUROPEAN COMMISION (2015) Boost for better spending of EU Cohesion Policy investments: Commisioner Cretu adopts new programme actvities for 2014-2020. Comunicado de prensa del 13 de febrero de 2015. Disponible en: <https:// ec.europa.eu/commission/commissioners/2014-2019/cretu/ announcements/boost-better-spending-eu-cohesion-policyinvestments-commissioner-cretu-adopts-new-programme en> [Consulta:18/07/2019]

- HUGO G. (2008) Immigrant settlement outside Australia's capital cities. Population, Space and Place, 2008

- MATEO PÉREZ, M. (2018) Expertos en desarrollo rural destacan que el programa europeo Leader ha generado identidad territorial. El Mundo Andalucía [en línea], 27 de agosto de 2018 <https://www.elmundo.es/andalu cia/2018/08/27/5b8428bd468aeb207e8b457c.html> [Consulta: 18/07/2019]

- SAMPEDRO GALLEGO, M. R. (2008) Cómo ser moderna y de pueblo a la vez: los discursos del arraigo y del desarraigo en las jóvenes rurales. Revista de Estudios de Juventud, n. ${ }^{\circ}$ 83, 2008, pp. 179-193

- WULFF, M.; CARTER, T.; VINEBERG, R. (2008) Attracting new arrivals to smaller cities and rural communities: findings from Australia, Canada and New Zealand. Journal of International Migration and Integration, vol. 9, n. ${ }^{\circ} 2,2008$, pp. 119-124 